\title{
Sucking and Swallowing Difficulties in Infancy: Diagnostic Problem of Dysphagia
}

\author{
R. S. ILLINGWORTH \\ From the Department of Child Health, University of Sheffield
}

The purpose of this paper is to review the world literature about dysphagia in infancy, and to provide a simple classification, illustrated here by a brief résumé of 19 personally observed cases. Finally, there is a short section on diagnosis and prognosis.

There is a lack of a good discussion of the whole problem of dysphagia in a textbook, whether paediatric, neurological, dental, or otorhinolaryngological. Indeed, many of the textbooks devoted to these subjects do not include the word dysphagia (or suitable synonym) in the index. Part of the difficulty may lie in the fact that affected children may be referred to any of a variety of specialistspaediatricians, otorhinolaryngologists, maxillofacial surgeons, plastic surgeons, and, later, speech therapists, so that few have adequate experience of the problem.

Accordingly I decided to review the literature, and apart from consulting all available textbooks devoted to the subjects of paediatrics, neurology, and otorhinolaryngology, I looked personally through 203 volumes of indices of the world literature-the Current List of Medical Literature, the Quarterly Cumulative Index Medicus, the Cumulative Index Medicus, and the Index Medicus, from volume 1 (1879) to December 1968, referring to all the papers quoted except two foreign articles (Bluhm, 1927; Dalloz, 1963) which I was unable to obtain. Most of the papers to which reference was made in these indices were under the heading of 'Deglutition, Disorders of'.

I have interpreted the word dysphagia broadly, to include rumination and difficulties with sucking.

For the purposes of this review, I propose to divide the references into two groups, those referring to gross structural abnormalities, and those referring to neuromuscular problems. There is a small amount of overlap between them.

\section{Gross Structural Abnormalities}

Many of these are referred to in reviews by Holinger, Johnston, and Potts (1951), Gaudier, Farriaux, and Delattre (1964), and Logan and Bosma (1967). They include congenital anomalies of the mouth, palate, jaw, temporo-mandibular joint, pharynx, postnasal space, larynx, oesophagus, and great vessels.

Anomalies in the mouth include cleft palate, submucous cleft, and macroglossia. While a cleft palate is obvious, a submucous cleft can be missed, the feeding difficulties and nasal regurgitation (and later the nasal speech) being ascribed to something else. A submucous cleft should be suspected when there is a bifid uvula and a palpable $\mathrm{V}$-shaped notch at the midline posterior border of the hard palate, replacing the normally palpable posterior nasal spine. There may be a thin translucent membrane replacing the median raphe, with a short palate.

An excessively large tongue may lead to feeding difficulties: Combs, Grunt, and Brandt (1966) described 3 children with so-called 'Beckwith's syndrome' of macroglossia, neonatal hypoglycaemia, microcephaly, and exomphalos. All babies were large at birth, had cyanotic attacks probably due to hypoglycaemia, and difficulty with feeding mainly because of the large tongue.

There have been numerous papers concerning the feeding difficulties associated with micrognathia, with or without cleft palate (Robin, 1923; 1934; Lenstrup, 1925; Eley and Farber, 1930; and Pruzansky and Richmond, 1954). It seems that the receding chin fails to support the tongue in its normal forward relation, and the tongue therefore slips back, impinges against the posterior wall of the pharynx, obstructing respiration and causing feeding difficulties and cyanotic attacks. Pierre Robin devised a method of feeding these 
babies in the prone position to facilitate normal swallowing.

Wilson, Kliman, and Hardyment (1963) described a case of congenital adherence of the tongue to the roof of the mouth, and termed this 'ankyloglossia superior'.

Maldevelopment of the temporo-mandibular joint is a rare but important cause of difficulty in feeding. Burket (1936) wrote a good review of this condition. It is sometimes associated with congenital hemiatrophy of the face. He described a full-term male infant with unilateral bony ankylosis of the temporomandibular joint, with consequent feeding difficulties. There was maldevelopment of the maxilla, presumably secondary to the abnormality in the joint. Kazanjian (1938) and Tratman (1939) mentioned cases, the former ascribing the underdevelopment of the jaw to involvement of the growth centre in the condyloid process; they described 33 cases in all, most of them, however, being of the acquired variety. Pettersson (1961) described a child with fusion of the jaws by a bony mass between the hard palate and the inside of the mandibular arch.

The subject of choanal atresia was well reviewed by Hobolth, Buchmann, and Sandberg (1967), who described 8 of their own cases. The obstruction consists of a bony or membranous plate behind the palate, causing obstruction of the airway. Affected infants suffer great distress when sucking on the breast, because up to the age of 5 months or so, they only breathe through the mouth when crying. After that age, the mouth is opened voluntarily when the nose is occluded.

Harrison, Fuqua, and Giffin (1965) wrote about a congenital laryngeal cleft, which causes symptoms suggestive of a tracheo-oesophageal fistula, and is liable to be associated with hydramnios during pregnancy. There are difficulties in feeding, with choking and stridor. There is a deep posterior cleft from the base of the arytenoid cartilages to the level of the laryngotracheal junction. The defect may be found in sibs, and it is not seen on direct laryngoscopy. The infant regurgitates through the tracheotomy tube. Mounier-Kuhn and Persillon (1955) referred to congenital absence of or deficiency of the posterior laryngeal wall causing feeding problems. Zachary and Emery (1961) described 3 cases ( 2 in sibs) of a persistent oesophago-trachea, causing swallowing difficulty: the larynx and trachea had not separated from the oesophagus.

Atkins (1968) described a child with feeding difficulties and symptoms suggestive of congenital laryngeal stridor; a lateral $x$-ray of the neck showed thickening of the retropharyngeal tissues. This was due to a duplication cyst of the oesophagus. Holinger et al. (1951) reviewed the various anomalies of the oesophagus associated with dysphagia and aspiration pneumonia. Kelley and Frazer (1966) wrote about webs in the oesophagus.

It was not felt necessary to refer to the many papers concerning feeding difficulties arising from congenital anomalies of the great vessels within the thorax-the so-called dysphagia lusoria.

\section{Neuromuscular Causes}

Several papers refer to dysphagia from which infants make a spontaneous recovery. Catel (1937) referred to these cases as 'hypertonicatonic dysphagia', and Nitsch (1954), using the same expression, ascribed it to a 'motility neurosis', stating that the difficulty tends to disappear within 12 to 18 months. Macaulay (1951) described a child who had to be tube fed for 3 weeks, and recovered fully by 10 months of age; there was an associated weakness of the right vocal cord. A lipiodol swallow showed that the larynx was not closed off during deglutition. Like Peiper (1942), he ascribed the difficulty to immaturity of the bulbar centres. Cohen (1955), Mounier-Kuhn and Persillon (1955), Béraud and Bastide (1956), and Ardran et al. (1965) ascribed cases to prematurity or brain damage. Ardran et al. described 5 affected infants who had to be tube fed for a few months; they found that improvement of swallowing resulted largely from the acquisition of compensatory movements of the tongue which squeezed the bolus through the pharynx. Frank and Gatewood (1966), and Matsaniotis, Karpouzas, and Gregoriou (1967) in each paper described 3 infants with transient pharyngeal incoordination which cleared in 2 weeks. Benson's (1962) case was tube fed for 6 months, and by 12 months was feeding normally, but had regurgitated fluid through the nose on one occasion at that age. This child was fully investigated by Ardran by cineradiography in infancy. He reported that there was inefficient sweeping back of the bolus by the tongue and poor propulsion into the pharynx. The soft palate was flaccid and its movements were incoordinated, so that it did not participate actively in guiding the bolus through the retro-oral opening or in preventing regurgitation into the nasal cavity. There were no co-ordinated contractions in the upper part of the pharynx; co-ordinated pharyngeal movements began at the level of the larynx. There was therefore incoordination of the muscles of the tongue, soft palate, and upper pharynx, resulting in faulty clearing of the laryngeal aditus and aspiration into the trachea. (In the ensuing discussion 2 members of the audience 
described cases recovering by 14 months and 4 years, respectively.) Farriaux, Walbaurm, and Fovet-Poingt (1964) described a child with palatal palsy who recovered by 29 months; he could not swallow until the age of 24 months. At 12 months he had developed an unexplained flaccid paraplegia. Schaffer in his textbook (1960) referred to the fact that some of these children after a period of gavage learn normal pharyngo-glottic coordination.

The principal papers on the more serious form of palatal palsy, which apparently does not recover in the early months, are those by Cohen (1955), Worster-Drought (1956), Graham (1964), and Ardran et al. (1965).

Cohen (1955), in his paper on congenital dysphagia, described five groups of cases: (a) cortical atrophy, hypoplasia, or agenesis ( 3 cases: one with spastic quadriplegia, one mentally defective child with isolated bulbar palsy, one defective child with paralysis of the cervical sympathetic and an anomalous right subclavian artery); (b) familial autonomic dysfunction (Riley, 1957, 2 cases); (c) familial paralysis of palate (1 case); (d) amyotonia congenita (1 case); (e) neurogenic oesophageal dysfunction (6 cases: cardiospasm, short oesophagus with spasm, Pierre Robin syndrome with chalasia, tracheo-oesophageal fistula, short oesophagus with hiatus hernia, and a child with atresia of the right ear, paralysis of the facial nerve, inspiratory stridor, hoarseness, and an oesophageal pouch).

Worster-Drought (1956) wrote that he had treated 82 cases of varying degrees of congenital suprabulbar paresis; 32 had the complete syndrome, with involvement of the tongue, palate, and orbicularis oris; in the remaining 50 , the soft palate was mainly or exclusively affected; in 10 the involvement was mainly of the tongue and palate, in 8 the tongue and orbicularis oris, in 6 the palate and orbicularis oris. Of the 82 cases, 2 had a cleft palate, 2 had a submucous cleft, 2 had congenital heart disease, and one had high frequency deafness. The IQ was average in 60 , and $50-70$ in 22 . He preferred the term suprabulbar paresis to 'pseudobulbar palsy', the term being intended to denote a lesion in the motor nerve pathway above the bulb or medulla, as distinct from the bulb itself or the bulbar nuclei. The main lesion lies in the motor nerve tract from the cortical motor areas for the tongue, palate, and lips, to the motor nuclei in the medulla, causing weakness and spasticity of the lips, tongue, palate, pharynx, and laryngeal muscles, with consequent dysphagia and later dysarthria. There is no fasciculation or wasting of the tongue, but the jaw jerk is exaggerated in almost all, and there is often jaw clonus. Involvement of the tongue is indicated by inability to move the tongue laterally or to curl it up, and involvement of the lips is shown by inability to purse or round the lips. He ascribed the condition to agenesis of the corticobulbar neurones. Some affected children have spastic quadriplegia.

Graham (1964), in his paper on 'Congenital flaccid bulbar palsy', wrote that bulbar palsy was usually supranuclear, as part of the cerebral palsy, but that the condition might be confined to the bulbar muscles. He described 10 cases, all with weakness of the palate. 7 had facial weakness or immobility, 2 had gross hypotonia, 2 had micrognathia, and 2 had wasting of the tongue. He suggested that some cases were due to a nonprogressive myopathy. One boy with facial and palatal palsy with micrognathia and a wasted tongue recovered completely by 14 years and attended a grammar-school.

Ardran et al. (1965) fully investigated 5 cases by cineradiography. All were tube fed for some months and one was fed by gastrostomy from 7 months to 4 years. 4 had palatal palsy. 3 had micrognathia, 2 had a bilateral facial weakness (one with a brisk jaw jerk), and one a lower motor neurone weakness of the facial nerve. All had paresis of the pharyngeal constrictor muscles. One was largely well at 1 year, one died at $4 \frac{1}{2}$ years, one at 5 still had weakness of the pharyngeal constrictors, and one was largely normal at 10 years. In one case they wrote that the bolus appeared to pass through the upper part of the pharynx mainly by gravity, and that peristaltic waves began at the level of the larynx.

In other papers there are shorter reports. Olmsted, Halfond, and Kirkpatrick (1960) described 3 cases of suprabulbar palsy and added 2 from the literature, not referred to in this paper. Still (1927) described a child with palatal weakness still present nearly 10 years after birth. Morgan (1956) described a case in which necropsy and histology of the brain revealed no abnormality. Upjohn (1957) described a case with left facial palsy, right vocal cord weakness, and right palatal and pharyngeal paralysis; for 3 months aspiration was required every 5 to 10 minutes. At 15 months there was still dysphagia, but less severe. Galdi and Gambirassi (1932) described one case of palatal palsy. Short references are made to the condition in the books by von Reuss (1920) and Ford (1966). The latter referred to 2 German papers by Peritz (1902), and Oppenheim and Vogt (1911).

The association of dysphagia with stridor is confused. I have discussed the diagnosis of stridor 
in detail elsewhere (1969), emphasizing that it has numerous important causes, even if it is purely inspiratory. The so-called congenital laryngeal stridor is not infrequently associated with swallowing difficulties (Ashby, 1906; and Apley, 1953). M'Kenzie (1925) described a child with severe inspiratory stridor, bulbar palsy, and a respiration rate of 9 to 10 per minute in sleep. No abnormality was found at necropsy. He reviewed the previous literature on congenital stridor, and suggested that stridor and dysphagia were due to congenital weakness in the framework of the introitus, the dysphagia resulting from secondary changes in the musculature. Schwartz (1953), in a paper on functional disorders of the larynx in infants, referred to the combination of congenital laryngeal stridor and dysphagia. Allen, Towsley, and Wilson (1954) described a child who developed stridor in response to various stimuli, such as swallowing. Chapple (1956) referred to swallowing difficulties with stridor associated with weakness of the superior branch of the laryngeal nerve, with facial palsy due to pressure and abnormal posture in utero.

Writers about the Möbius syndrome of congenital facial diplegia refer to dysphagia as an early symptom. Evans (1955) described 9 cases, in 5 of which there was weakness of the palate. One child, with swallowing problems from birth, had bilateral palatal and unilateral facial palsy; fluid came down the nose on swallowing until the age of 9 years. Another case had an immobile palate, stridor, dysphagia, micrognathia, and wasting and fasciculation of the tongue. A third child had bilateral facial palsy, with weakness of the palate and tongue; a fourth had micrognathia, a wasted tongue, weak palate, bilateral facial weakness, and possibly weakness of the masseter; another child had the Klippel-Feil syndrome, with bilateral external rectus weakness, unilateral facial palsy, stridor, and micrognathia. Nisenson, Isaacson, and Grant (1955) described similar cases.

Dodge et al. (1965) described 7 children with sucking and swallowing difficulties from birth, with general weakness, hypotonia, facial diplegia, and retarded motor development, whom they considered to have myotonic dystrophy. There was bulbar weakness in all but one. In no case was the weakness progressive. There was usually percussion myotonia, and the electromyogram was abnormal in all.

Cohen (1955) thought that 'amyotonia' was a cause of dysphagia; 2 of Graham's cases (1964) and 3 of those described by Matsaniotis et al. (1967) had severe hypotonia.
McGibbon and Mather (1937) and Cohen (1955) described infants with swallowing problems due to spasm of the oesophagus. Holinger et al. (1951) wrote about achalasia in infancy.

A peculiar feeding or swallowing problem is that of rumination. In 1911 Sawyer wrote a vivid description of what my colleague, Dr. Ronald Gordon, aptly termed 'gargling rumination'. Sawyer described 5 infants who when given liquids in the upright position opened and closed the mouth in rhythmical manner, 'reminding one of movements made by a fish' and 'appearing to gargle with the milk'. He ascribed it to temporary incoordination of the swallowing mechanism. Cameron (1925) wrote that rumination never occurred before the fourth month, but Stein, Rausen, and Blau (1959) wrote that it might begin as soon as 5 weeks. Cameron wrote that the head of the column of milk might be momentarily visible many times as it attained its highest point, only to fall back again, with innumerable masticatory movements. He added that it was characteristic of the ruminating child that he sinned his sins only in secret; to watch him openly was to stop the whole procedure. Richmond, Eddy, and Green (1958) and Stein et al. (1959) regard it as a psychosomatic problem, and a call for more love and fondling.

The movements of rumination are somewhat reminiscent of tongue thrusting, commonly seen in rhythmical form among athetoid infants, and referred to in speech therapy journals (e.g. Palmer, 1962).

Dysphagia in the newborn may be due to myasthenia (Kibrick, 1954). It is a feature of familial dysautonomia. Cohen (1955) described 2 children with Riley's syndrome, with symptoms suggesting a tracheo-oesophageal fistula. Riley (1957) says that practically all cases of familial dysautonomia have feeding problems from birth, and that several have to be tube fed for the first few months. $\mathrm{He}$ ascribes the problem to a 'basically deranged swallowing reflex'.

Dysphagia is a common feature of the Prader Willi syndrome. Zellweger and Schneider (1968) added 79 cases from the literature to 14 of their own for the purposes of a review. These authors think that sucking and swallowing reflexes tend to be weak or absent. 7 of their 14 cases were tube fed for several weeks. After several months the feeding difficulties tended to disappear, and to be replaced by hyperphagia.

Takagi and Bosma (1960) described an infant with feeding problems, due, they thought, to inhibition of the normal tongue and palate move- 


\section{Sucking and Swallowing Difficulties in Infancy: Diagnostic Problem of Dysphagia}

ments by abnormalities of the cervical postural mechanisms. The tongue was caudally displaced, the mandible retruded, and the tongue and hyoid were insufficiently supported by the mandible. Swallowing was adequate in a variety of head neck positions, but suckling only occurred when the neck was extended, preferably in the prone, and best in opisthotonos. He sucked well on his side if the head was extended, suggesting that the position of the neck was the essential factor.

Several papers refer to feeding difficulties in the Cornelia de Lange syndrome (Ptacek et al., 1963; Silver, 1964). Silver described difficulties in sucking and swallowing, with episodes of rcgurgitation, aspiration, and cyanotic attacks.

Dysphagia is a common feature of tetanus neonatorum. Marshall (1968), writing about his vast experience of this condition in Haiti, wrote that the first symptom was commonly difficulty in sucking at the age of 5 or 6 days; the jaws then became stiff and swallowing became impossible.

It is interesting but not surprising that hydramnios had occurred in so many of the cases to which reference has been made; Kazanjian (1938) noted it in the case of ankylosis of the temporo-mandibular joint, Harrison et al. (1965) in the case of laryngeal cleft, and Matsaniotis et al. (1967) mentioned it in 5 cases of dysphagia; Graham (1964), Ardran et al. (1965), and Logan and Bosma (1967) also described it.

Several workers noted a familial factor in some of their cases. Worster-Drought described 7 familial cases in the 82 children with suprabulbar palsy; there were affected cases in 2 sisters and a daughter of one case; a father and his boy and girl; 2 brothers and a cousin; a mother and son; 2 brothers and a sister; and twin brothers. Cohen described an affected child of a mother and her first husband, and 3 affected children out of 5 from the mother and her second husband. Tamm (1925) referred to familial cases. Harrison et al. (1965) found a laryngeal cleft in a sib.

The frequency of pulmonary complications, often leading to a primary diagnosis of pulmonary disease instead of a diagnosis of one of the causes of dysphagia, was mentioned by numerous workers: Holinger et al. (1951), Thieffrey and Job (1954), Bernheim et al. (1955), Cohen (1955), MounierKuhn and Persillon (1955), Béraud and Bastide (1956), Bastide (1957), Ardran et al. (1965), Frank and Gatewood (1966), and Matsaniotis et al. (1967). Many of these workers emphasized the similarity of the symptoms of dysphagia of various causes to those of tracheo-oesophageal fistula. Cohen (1955), for instance, noted this in a case of Riley's syndrome, and Harrison et al. (1965) in the case of laryngeal cleft.

With regard to aetiology and classification, which the above references to the literature show to be at present thoroughly confusing, it certainly seems reasonable in the first place to divide cases of dysphagia into 2 main groups-those with gross congenital anatomical defects, and those with neuromuscular disorders. There is little overlap between those groups; but the incidence of micrognathia in the second group (neuromuscular disorders) is interesting; it was mentioned in 3 of the children with the so-called Möbius syndrome described by Evans (1955), 2 of the 10 palatal palsy cases described by Graham (1964), and 3 of the 5 described by Ardran et al. (1965).

The neuromuscular group is more difficult. It certainly seems reasonable to include delayed maturation. The swallowing mechanism is complicated, and the small premature baby cannot suck and swallow adequately. As the mentally defective full-term infant is backward in all aspects of development, he behaves like a premature baby, and commonly has similar swallowing difficulties. Furthermore, delayed maturation is seen in many areas of development-in auditory and visual responses, in sitting, walking, talking, acquiring sphincter control, and in reading, and it would be expected that delayed maturation, perhaps familial, would be seen in the complicated process of deglutition. In the case of cerebral palsy, there is likely to be a combination of factors-prematurity, mental subnormality, spasticity and incoordination of muscles, and cortical defects.

The greatest difficulty concerns the group ascribed to abnormalities of the cranial nerve nuclei or the tracts to them. Palatal palsy, tongue weakness, pharyngeal incoordination, or weakness of other muscles, especially facial, may be due to several different conditions, and any combination of these may perhaps be due to one or more pathological processes, some children, as Worster-Drought pointed out, having predominantly one part involved and some predominantly another.

The frequency of inspiratery stridor in children with dysphagia was noted (e.g. M'Kenzie, 1925; Chapple, 1956; Apley, 1953; and Cohen, 1955), but the mechanism of the association is not understood. The frequency of facial weakness in these children is interesting. Looking at these case histories all together, it is impossible to distinguish those described by Evans (1955) as the Möbius syndrome from the other children (e.g. those described by Graham (1964) as congenital palatal palsy). 5 of Evans's 9 cases 
had palatal palsy; 7 of Graham's 10 cases and 3 of the 5 described by Ardran et al. (1965) had facial weakness. It is clear that a variety of other cranial nerves may be involved in some of these cases of bulbar or pseudobulbar palsy, and that if the facial nerve is involved, they are apt to be given the eponym of the Möbius syndrome. It is uncertain as yet whether this syndrome is an entity or not; if it is, there is considerable overlap with the other cases described. The occasional presence of micrognathia and certain other features suggests that there may even be overlapping between the neuromuscular group and some with those having gross anatomical defects, such as those with hypoplasia of the temporo-mandibular joint.

Henderson (1939), in his review of 61 cases of the Möbius syndrome, found 6 with dysphagia, 4 with bilateral palatal palsy and nasal regurgitation, 18 with paresis or hypoplasia of the tongue, and 2 with fasciculation in the tongue. Inability to suck, as distinct from dysphagia, was frequent. 51 had other cranial nerve palsies, and 29 had other major deformities -19 of them with talipes and 8 with hypoplasia of pectoralis major. There were 4 instances of 2 or more affected children in a family.

In his original paper Möbius (1888) described a 50-year-old man with weakness of both hands, bilateral facial weakness, ptosis, bilateral 6th nerve palsy, and drooping of the mouth. There was no note about the palate.

The distinction of suprabulbar from bulbar palsy seems in the present state of our knowledge to be more a matter of academic interest than of practical importance. It is uncertain whether the prognosis is different in the two groups. Jaw clonus and an exaggerated jaw jerk suggest a suprabulbar palsy, and wasting of the tongue (e.g. Evans, 1955; Graham, 1964) suggests a neurogenic atrophy. It certainly seems that the cranial nerve group should be distinguished from the group with no apparent abnormality apart from incoordination of the swallowing mechanism. The association with the hypotonias (e.g. Cohen, 1955; Graham, 1964; Matsaniotis et al., 1967; and the Prader Willi and Riley syndromes) is interesting, but not understood. Hypotonia is the end result of a wide variety of conditions (Dubowitz, 1968). Nor is it easy to fit in the paper by Dodge et al. on myotonic dystrophy. With regard to chalasia and achalasia of the oesophagus, it is uncertain whether this may on occasion be analogous to incoordination higher up the alimentary tract. In the great majority of cases in the literature (and in my own cases), there was a notable absence of a history of severe birth difficulties such as would suggest birth injury.

Further study by muscle biopsy and histochemistry, by electromyography, and other procedures, may well elucidate some of those problems and delineate the role of muscle disease in the group of dysphagias. Much more study is required to increase our understanding of these children.

\section{Suggested Classification of Dysphagia in the Newborn}

The following suggested classification will almost certainly not stand the test of time, as more knowledge is acquired. In preparing it, I have tried to avoid the two dangers of oversimplification and overelaboration. (Conditions confined to older children - such as attention-seeking devices, the effect of corrosives on the upper alimentary tract, degenerative diseases of the nervous system, and many other neurological conditions have been excluded.)

\section{Gross congenital anatomical defects}

Palate: Cleft palate, submucous cleft.

Tongue: Macroglossia; cysts, tumours, lymphangioma; ankyloglossia superior; ? tongue tie, extreme.

Retronasal space: Choanal atresia.

Mandible: Micrognathia; Pierre Robin syndrome.

Temporo-mandibular joint: Ankylosis, congenital, or result of osteitis; hypoplasia.

Pharynx: Cyst, diverticulum, tumour.

Larynx: Cleft, cyst, defects.

Oesophagus: Atresia, stenosis, short oesophagus, web, diverticulum, duplication, lung buds. Tracheo-oesophageal fistula.

Thorax: Abnormalities of great vessels; dysphagia lusoria.

\section{Neuromuscular causes}

Delayed maturation: Prematurity, mental deficiency, normal variation.

Cerebral palsy: Spastic or athetoid type.

Abnormality of cranial nerve nuclei or tracts to them.

Bulbar and suprabulbar palsy.

'Möbius syndrome'.

Pharyngeal or cricopharyngeal incoordination.

Congenital laryngeal stridor.

Chalasia or achalasia of oesophagus.

Muscular dystrophy, myotonic dystrophy, myasthenia, hypotonias. 


\section{Sucking and Swallowing Difficulties in Infancy: Diagnostic Problem of Dysphagia}

Tetanus.

Diphtheria.

Poliomyelitis.

Syndromes-Cornelia de Lange

Riley

Prader Willi

Cervical postural (Tagaki and Bosma)

Rumination, tongue thrusting.

\section{Acute infective conditions \\ Stomatitis \\ Oesophagitis.}

\section{Illustrative Case Reports}

Case 1: Suprabulbar palsy with eventual recovery. Hydramnios. Gross swallowing difficulty from birth. Weak hoarse cry, palatal palsy, limbs abnormally extended, legs crossed when held by hand in axilla. Knee jerks exaggerated, sustained ankle clonus. Diagnosis of suprabulbar palsy with spastic quadriplegia, but eyes constantly rolling and highly abnormal hand movements suggested athetosis. Had to be sucked out every 15 to 20 minutes; tube fed for 4 months.

8 weeks: signs of spasticity regressing; began to smile, but kept head retracted.

26 weeks: still had to be sucked out 4 times a day. Spastic approach to objects; transferring from hand to hand; knee jerks normal.

8 months: sat, no support. Only abnormal sign was abnormal approach to object with hand.

11 months: still sucked out 3 times a day.

8 years: clumsy child, some tremor of hands; no other abnormality. On Goodenough draw-a-man test, Goddard formboard, repeating digits-normal for age.

10 years: absolutely no disability. Palate and speech normal. Average performance at school in normal class for age. Plantar responses flexor. No clumsiness. Slight tremor of hands on fine manipulation (within normal limits).

Case 2: Suprabulbar palsy with eventual death. Gross swallowing difficulty from birth. Signs of spastic quadriplegia. Palatal palsy, jaw clonus, exaggerated knee jerk. Tube fed from birth. Some micrognathia. Jaw opening very restricted, presumably because of spasm of masseters. Cineradiography: normal swallowing only when bolus reached hypopharynx.

21 months: still tube fed. No signs of spasticity. Died at 4 years.

Case 3: Incoordination of swallowing mechanism. Palate normal. Tube fed for 8 months. Repetitive tongue thrusting, as in athetosis. Delayed motor development.

16 months: cineradiography; incoordination of swallowing and tongue movements.

27 months: DQ 85. No feeding difficulty.

7 years: a slightly clumsy child (minimal ataxia) with no disability; no other abnormal neurological signs; a normal-looking girl at ordinary school.

Case 4: Hypoplasia of temporo-mandibular joint, with cranial nerve weakness. Tube fed for 8 months. Right facial weakness, palatal palsy, microcephaly. No other signs. At birth could not open mouth. Lies with head retracted. Maximum opening of jaw with curare only a few centimetres, without curare $13 \mathrm{~mm}$. $X$-rays and examination under curare suggested maldevelopment of condyle. Died of aspiration pneumonia aged 4 years. No necropsy.

Case 5: Restricted opening of mouth with incoordination of swallowing. Tube fed for 9 months. First seen by me at 16 months. At 17 months maximum opening of jaw under anaesthetic and relaxant $3 \mathrm{~cm}$. No other neurological signs. DQ average. EMG of masseters normal.

3. 0 years: still chokes on solids.

$5 \cdot 3$ years: jaw opens a little better.

7.4 years: normal-looking child; IQ 80; mouth opens virtually normally. Speech and palate normal. Some incoordination of swallowing of liquids, with a trick movement of tongue on swallowing solids, but it presents no difficulty. No residual disability.

The remaining 14 cases are shown in the Table.

\section{Comment on Case Reports}

All 19 children had swallowing difficulties of various degrees in infancy. Two (Cases 4 and 5) had severe limitation in opening the mouth. This was thought after examination under anaesthesia to be due to bone or fibrous tissue, and not spasm; but even these children seemed to overlap somewhat with the 'spasm' group, because difficulty in opening the mouth would not by itself have made tube feeding necessary for 8 or 9 months. One of them (Case 4) had palatal palsy and right facial weakness, and the other (Case 5) choked even at 3 years when given solids. It was most surprising to find that at the age of 7 years she was opening the mouth normally, and there was no disability, though swallowing was not normal. The diagnosis in retrospect was not at all clear. Another child (Case 18) proved to have a vascular ring and the other (Case 19) had a submucous cleft.

The remaining 15 fell into the 'neuromuscular' group. 2 had typical suprabulbar palsy, both with early signs of spastic quadriplegia, both losing all signs of this before the first birthday; in one the sole remaining sign was 'clumsiness' (cf. cases of Ardran et al., 1965; Olmsted et al., 1960). 2 mentally subnormal children had bulbar palsy. 6 were thought originally to have the Möbius syndrome, but they closely resemble the other cases in this 
TABLE

Cases of Dysphagia in the Newborn Period

\begin{tabular}{|c|c|c|c|c|c|}
\hline \multirow{2}{*}{$\begin{array}{l}\text { Case } \\
\text { no. }\end{array}$} & \multirow{2}{*}{ Diagnosis and Sex } & \multirow{2}{*}{ Other Abnormal Signs } & \multicolumn{2}{|r|}{ Follow-up } & \multirow[b]{2}{*}{ IQ } \\
\hline & & & $\begin{array}{l}\text { Age } \\
\text { (yr.) }\end{array}$ & Findings & \\
\hline 6 & Bulbar palsy, $\mathbf{M}$ & None & 5 & $\begin{array}{l}\text { Only occasional swallowing difficulty; } \\
\text { palate weakness }\end{array}$ & 62 \\
\hline 7 & Bulbar palsy, $\mathrm{F}$ & Retarded development & 15 & Palatal palsy; severe speech defect & $\begin{array}{l}\text { ESN (IQ } \\
50-70 \\
\text { range) }\end{array}$ \\
\hline 8 & Möbius syndrome, $F$ & $\begin{array}{l}\text { Bilateral facial palsy, bilateral } \\
\text { external rectus palsy; paresis } \\
\text { of palate; bifid uvula; } \\
\text { sluggish corneal reflex; tongue: } \\
\text { weak in all directions, deeply } \\
\text { grooved; fasciculation; cine- } \\
\text { radiography, defective tongue } \\
\text { action and incoordination of } \\
\text { swallowing }\end{array}$ & 12 & Slight dysphagia only & 79 \\
\hline 9 & Möbius syndrome, $\mathbf{M}$ & $\begin{array}{l}\text { Palate weak, right facial weakness; } \\
\text { right external rectus palsy; } \\
\text { hemiatrophy of tongue; } \\
\text { abnormal finger-nails }\end{array}$ & 5 & Some dysphagia & ESN \\
\hline 10 & Möbius syndrome, $M$ & $\begin{array}{l}\text { Bilateral facial palsy; syndactyly; } \\
\text { external rectus palsy; talipes }\end{array}$ & 7 & Palate normal; speech indistinct & $\begin{array}{l}\text { Normal } \\
\text { school; } \\
\text { backward }\end{array}$ \\
\hline 11 & Möbius syndrome, $\mathbf{M}$ & $\begin{array}{l}\text { Left facial weakness; syndactyly; } \\
\text { bilateral external rectus palsy; } \\
\text { micrognathia }\end{array}$ & 7 & No disability; signs persist & $\begin{array}{l}\text { Normal } \\
\text { school }\end{array}$ \\
\hline 12 & Möbius syndrome, $\mathrm{F}$ & $\begin{array}{l}\text { Complete bilateral } 4 \text { th, } 6 \text { th, and } \\
\text { 7th nerve palsy; ptosis; } 12 \text { th } \\
\text { nerve palsy; palate weak; } \\
\text { wasting of tongue; fascicu- } \\
\text { lation }\end{array}$ & 10 & No dysphagia; palsies persist & $\begin{array}{l}\text { Normal } \\
\text { school }\end{array}$ \\
\hline 13 & Möbius syndrome, $\mathbf{M}$ & $\begin{array}{l}\text { Facial weakness, micrognathia, } \\
\text { deformity of feet }\end{array}$ & 20 & No disability & $\begin{array}{l}\text { Mentally } \\
\text { retarded }\end{array}$ \\
\hline 14 & Möbius syndrome, $F$ & $\begin{array}{l}\text { Right facial weakness, bilateral } \\
\text { external rectus palsy, maternal } \\
\text { hydramnios }\end{array}$ & 9 & Signs persist & $\begin{array}{l}\text { Normal } \\
\text { school }\end{array}$ \\
\hline 15 & $\begin{array}{l}\text { Incoordination of } \\
\text { swallowing } \\
\text { mechanism, F }\end{array}$ & None & & Died from pneumonia at $9 \mathrm{mth}$. & \\
\hline 16 & Hypotonia, M & Expressionless face & $1 \cdot 3$ & Hypotonia persists & \\
\hline 17 & Hypotonia, M & Hearing defect & 6 & Hypotonia persists & $\begin{array}{l}\text { Mental } \\
\text { defect }\end{array}$ \\
\hline $\begin{array}{l}18 \\
19\end{array}$ & $\begin{array}{l}\text { Vascular ring, } M \\
\text { Submucous cleft of } \\
\text { palate, } M\end{array}$ & Stridor & 8 & Cured by operation & $\begin{array}{l}\text { Severe } \\
\text { mental } \\
\text { defect }\end{array}$ \\
\hline & & & & & \\
\hline
\end{tabular}

series, and as already stated, it is doubtful whether the Möbius syndrome is an entity. 2 children showed incoordination of swallowing without bulbar palsy and 2 showed hypotonia with a normal palate. The low mean IQ of the whole neuromuscular group is striking.

The most notable feature of the follow-up examination was the remarkable improvement in many of these children, with the absence of disability at school age in children who had the most severe disabilities in infancy. The follow-up examination strongly impressed me with the great difficulty of giving a prognosis in infancy, even when the infant had to be tube fed for many months.

\section{Mechanics of Swallowing}

The normal swallowing mechanism, described by Cohen (1955) consists of three phases.

(1) Buccal pharyngeal phase (under voluntary control). The food or liquid is pushed back upon the dorsum of the tongue and is rolled back by the tongue to lie in front of the fauces. The oral, nasal, and laryngeal surfaces are closed by the lips, tongue, and palate, as the larynx moves upwards. The myelohyoid muscle contracts and presses the tongue against the hard palate. This movement pushes the bolus downward into the pharynx as the 


\section{Sucking and Swallowing Difficulties in Infancy: Diagnostic Problem of Dysphagia}

larynx returns to its normal position. This is a reflex action caused by stimulation of sensory areas on the mucosa of the tongue, soft palate, and posterior wall of the pharynx. Stimulation of these receptor organs by contact with the oral contents causes efferent stimuli to be carried by the glossopharyngeal nerve, the second division of the fifth nerve, and superior laryngeal nerve, to the swallowing centre in the floor of the fourth ventricle. Anaesthetizing these receptors makes swallowing virtually impossible.

(2) Oesophageal phase. This follows reflexly with relaxation of the cricopharyngeal sphincter and the oesophagus as a whole. Liquids drop by gravity to the ampullary end, and solids move by peristalsis.

(3) Cardiogastric phase. This begins as swallowed material reaches the ampulla. The closing mechanism of the oesophagus relaxes in quick periods to permit gushes of food to enter the stomach.

\section{Diagnosis of Dysphagia}

The symptoms of dysphagia include difficulty in sucking and swallowing, vomiting, nasal regurgitation of liquids, often a cough because of inhalation of food, and sometimes stridor and hoarseness. The developmental history is essential, because of the frequent association with mental subnormality.

The first step in the examination is to observe the child's face and limb movements. Thieffrey and Job (1954) suggested that he should then be watched taking a drink of water. The examination must include the cranial nerves, not forgetting the pursing of the lips, the jaw jerk, jaw clonus, and lateral movements of the tongue (and if possible the curling-up of the tongue). The latter can be tested for by eliciting the cardinal points or mouthing reflexes described by various workers (Illingworth, 1970). The sucking can be assessed by allowing the baby to suck one's finger; this enables one to determine whether the problem is primarily one of sucking (as in some of the infants with facial palsy), or of swallowing. The tongue should be examined for wasting and fasciculation, the movements of the palate noted, and if indicated, the movements of the vocal cords. The frequent involvement of the facial and eye muscles is remembered. One must look for the early signs of cerebral palsy (Illingworth, 1970), and carry out a full developmental examination (which, in the first month or two, can only take a few minutes).
The maximum head circumference related to the child's weight can on no account be omitted, because if the head is small in relation to the size of the baby, and there is also developmental retardation, mental subnormality will be suspected.

Special investigations include laryngoscopy (if there is stridor), oesophagoscopy (where indicated), lateral $x$-ray of the neck to show the airway, lipiodol swallow (unless tracheo-oesophageal fistula is suspected, when we prefer not to use an opaque substance if possible), and particularly cineradiography. The technique of cineradiography for these cases has been described in detail by Ardran and Kemp (1956), Béraud and Bastide (1956), Bastide (1957), and Farriaux and Milbled (1967). Some workers prefer to postpone detailed radiological investigation at least for 3 or 4 weeks, in case the dysphagia is a matter of delayed maturation and will soon cure itself, for cineradiography involves a fairly considerable amount of irradiation. For suspected anomalies of the great vessels, the usual radiological investigations are essential.

\section{Prognosis}

Leaving aside the group of cases due to gross congenital anatomical conditions, whose treatment and therefore prognosis depends on the cause and what can be done for it, one is left with the large miscellaneous group of cases due to neuromuscular disorders. Experience of one's own cases, and a review of the literature, leaves one with a feeling of great difficulty with regard to the prognosis for the dysphagia and for the intellectual development. In some children in whom it is thought that the dysphagia is due to delayed maturation of the swallowing mechanism, recovery may be complete over varying periods; in some the recovery may be only partial. Those with bulbar or suprabulbar palsy, or mere incoordination, may lose their symptoms in a week or two, or recover after several years. Even if the disability is permanent, the child may learn to compensate at least in part by trick movements of the tongue.

If the bulbar or suprabulbar palsy is part of a spastic quadriplegia, the outlook can only be bad; but abnormal neurological signs in the first weeks may disappear. Unless the quadriplegia is severe, and associated with microcephaly, one cannot be sure that it will be permanent. To put it differently, if a child shows signs of only mild spastic quadriplegia, is developmentally normal, and has a normal head circumference in relation to his size, there is a good chance that the signs will disappear in a few months. Whether in later 
childhood he will prove to be a 'clumsy child' remains to be seen.

Whether or not there are other signs of cerebral palsy, a full developmental assessment is essential, because the prognosis is inevitably worse if there is mental subnormality.

It must always be remembered that when there is a congenital abnormality, there is always an increased risk of mental retardation. In an unpublished series of 1068 mentally subnormal children seen by me, without cerebral palsy, cretinism, or mongolism, $313(29.3 \%)$ had congenital abnormalities. The high incidence of mental subnormality in the syndromes of Riley, Beckwith, Prader Willi, and Cornelia de Lange is well known.

Of Worster-Drought's series of 82 children with suprabulbar palsy, 60 had an average IQ and 22 were educationally subnormal. (Many of the more severely affected cases would have died before they reached Worster-Drought at school age.) 2 of the 5 described by Ardran et al. (1965) were seriously subnormal (IQ below 50). There can be no doubt that, as Cohen wrote, some of the cases of bulbar palsy are associated with gross cerebral defects; but some are mentally normal.

There are 2 special difficulties with regard to prediction. One is the sensitive or critical period (Illingworth and Lister, 1964); the other is pseudoretardation. With regard to the sensitive or critical period, we pointed out that if babies are not given solid food (as distinct from thickened feeds) when they have recently learnt to chew (average age 6 to 7 months), they will refuse solids later or vomit them. When, therefore, a child with dysphagia is deprived of solid foods at the sensitive period, but given them subsequently, the vomiting and food refusal may be mistaken for the primary condition, when in fact it is due to the child passing the critical period without having been given solids. We gave examples of this problem in our paper.

Children with dysphagia which persists for more than a few weeks are especially liable to suffer pseudoretardation as a result of their stay in hospital and separation from their mothers. Hence it would be easy to make a wrong diagnosis of mental subnormality in a mentally normal child. It is difficult or impossible to decide how much of this retardation will be reversible when the child is returned to a good home.

\section{Summary}

A comprehensive review of the world literature on dysphagia in infancy proved the subject to be thoroughly confused.
Dysphagia is the end result of a wide variety of pathological processes, notably gross congenital anatomical defects and neuromuscular abnormalities.

On the basis of the literature and the author's own experience, a classification is provided, which aims to avoid the dangers of oversimplification and overelaboration.

Some clues as to the probable outcome of these cases are offered.

I wish to thank the following consultants for referring their patients to me, or for advising me in the preparation of this paper; W. Hynes, B. S. Crawford, J. T. Buffin, A. Young, J. H. Gardiner, F. R. M. Elgood, F. P. Hudson, V. Dubowitz, J. Diggle, C. C. Harvey, B. W. Powell, E. G. G. Roberts, S. E. Keiden, D. Stone, and B. A. M. Smith. My Lecturer in Child Health, Dr. Frank Harris, kindly read and criticized the entire script.

I particularly wish to thank Mr. P. Wade, Librarian of the Royal Society of Medicine, for his help in finding many of the journals listed.

\section{REFERENCES}

Allen, R. J., Towsley, H. A., and Wilson, J. L. (1954). Neurogenic stridor in infancy. Amer. F. Dis. Child., 87, 179.

Apley, J. (1953). The infant with stridor. A follow-up survey of 80 cases. Arch. Dis. Childh., 28, 423.

Ardran, G. M., Benson, P. F., Butler, N. R., Ellis, H. L., and McKendrick, T. (1965). Congenital dysphagia resulting from dysfunction of the pharyngeal musculature. Develop. Med. Child Neurol., 7, 157.

- - , and Kemp, F. H. (1956). Radiologic investigation of pharyngeal and laryngeal palsy. Acta radiol. (Stockh.), 46, 446.

Ashby, H. (1906). A discussion on congenital stridor (laryngeal and tracheal). Brit. med. F., 2, 1488.

Atkins, J. P. (1968). Some aspects of benign esophageal disease in children. Ann. Otol. (St. Louis), 77, 883.

Bastide, R. (1957). Contribution à l'étude radiologique des troubles de la déglutition chez le nourrisson et le jeune enfant. $\mathcal{f}$. Radiol. Electrol., 38, 663.

Benson, P. F. (1962). Transient dysphagia due to muscular incoordination. Proc. roy. Soc. Med., 55, 237.

Béraud, C., and Bastide, R. (1956). Étude radiologique des troubles fonctionnels de la déglutition chez le nouveau-né et le jeune enfant. F. Radiol. Electrol., 37, 420.

Bernheim, M., François, R., Roux, J. A., and Mouriquand, C. (1955). Quelques aspects étiologiques des accidents de la déglutition dans la période néonatale. Pediatrie, 10, 70.

Bluhm, A. (1927). Kau- und Schluckstörung auf erblicher Grundlage. Arch. Rass.-u. Ges. Biol., 20, 72.

Burket, L. W. (1936). Congenital bony temporomandibular ankylosis and facial hemiatrophy. F. Amer. med. Ass., 106, 1719.

Cameron, H. C. (1925). Some forms of vomiting in infancy. Brit. med. $\mathcal{F} ., 1,872$.

Catel, W. (1937). Hypertonisch-atonische dysphagie bei Säuglingen mit habituellem Erbrechen. Klin. Wschr., 16, 296.

Chapple, C. C. (1956). A duosyndrome of the laryngeal nerve. Amer. F. Dis. Child., 91, 14.

Cohen, S. R. (1955). Congenital dysphagia. Neurogenic considerations. Laryngoscope (St. Louis), 65, 515.

Combs, J. T., Grunt, J. A., and Brandt, I. K. (1966). New syndrome of neonatal hypoglycemia; association with visceromegaly, macroglossia, microcephaly and abnormal umbilicus. New Engl. F. Med., 275, 236.

Dalloz, J. C. (1963). Les troubles de la déglutition chez le nouveauné et le jeune nourrisson. Vie méd., 44, 24.

Dodge, P. R., Gamstorp, I., Byers, R. K., and Russell, P. (1965). Myotonic dystrophy in infancy and childhood. Pediatrics, 35, 3. 
Dubowitz, V. (1968). The floppy infant: a practical approach to classification. Develop. Med. Child. Neurol., 10, 706.

Bley, R. C., and Farber, S. (1930). Hypoplasia of the mandible (micrognathy) as a cause of cyanotic attacks in the newly born infant. Amer. F. Dis. Child., 39, 1167.

Evans, P. R. (1955). Nuclear agenesis. Möbius' syndrome; the congenital facial diplegia syndrome. Arch. Dis. Childh., 30, 237.

Farriaux, J. P., and Milbled, G. (1967). Deglutition in the newborn. Med. biol. Ill., 17, 191 .

-, Walbaurm, R., and Fovet-Poingt, O. (1964). Trouble de la déglutition à début néo-natal. Presse méd., 72, 759.

Ford, F. R. (1966). Diseases of the Nervous System in Infancy, Childhood and Adolescence. 5th ed. Charles Thomas, Springfield, Illinois.

Frank, M. M., and Gatewood, O. M. (1966). Transient pharyngeal incoordination in the newborn. Amer. F. Dis. Child., 111, 178.

Galdi, F., and Gambirassi, A. (1932). Ausencia de reflejo de deglución en un lactante de 6 meses y medio. Rev. Asoc. méd. argent., 45, 1597.

Gaudier, B., Farriaux, J. P., and Delattre, B. (1964). Pathologie de la déglutition en pédiatrie. I. Anomalies congénitales et troubles de la déglutition. Acta paediat. belg., 18, 5 .

Graham, P. J. (1964). Congenital flaccid bulbar palsy. Brit. med. f., $2,26$.

Harrison, H. S., Fuqua, W. B., and Giffin, R. B., Jr. (1965). Congenital laryngeal cleft. Amer. F. Dis. Child., 110, 556.

Henderson, J. L. (1939). The congenital facial diplegia syndrome: clinical features, pathology and aetiology. A review of 61 cases. Brain, 62, 381.

Hobolth, N., Buchmann, G., and Sandberg, L. E. (1967). Congenital choanal atresia. Acta paediat, scand., 56, 286.

Holinger, P. M., Johnston, K. C., and Potts, W. J. (1951). Congenital anomalies of the esophagus. Ann. Otol. (St. Louis), 60, 707.

Illingworth, R. S. (1970). The Development of the Infant and Young Child: Normal and Abnormal. 4th ed. Livingstone, Edinburgh. - (1969). Common Symptoms of Disease in Children, 2nd ed. Blackwell, Oxford.

-, and Lister, J. (1964). The critical or sensitive period, with special reference to certain feeding problems in infants and children. F. Pediat., 65, 839.

Kazanjian, V. H. (1938). Ankylosis of the temporomandibular joint. Surg. Gynec. Obstet., 67, 333.

Kelley, M. L., Jr., and Frazer, J. P. (1966). Symptomatic midesophageal webs. F. Amer. med. Ass., 197, 143.

Kibrick, S. (1954). Myasthenia gravis in the newborn. Pediatrics, 14, 365.

Lenstrup, E. (1925). Hypoplasia mandibulae as cause of choking fits in infants. Acta paediat. (Uppsala), 5, 154

Logan, W. J., and Bosma, J. F. (1967). Oral and pharyngeal dysphagia in infancy. Pediat. Clin. N. Amer., 14, 47.

Macaulay, J. C. (1951). Neuromuscular incoördination of swallowing in the newborn. Lancet, 1, 1208.

McGibbon, J. E. G., and Mather, J. H. (1937). Simple nonsphincteric spasm of the oesophagus. ibid., 1, 1385.

M'Kenzie, D. (1925). Congenital laryngeal stridor with dysphagia. f. Laryng., 40, 285.

Marshall, F. N. (1968). Tetanus of the newborn: with special reference to experiences in Haiti. Advanc. Pediat., 15, 65.

Matsaniotis, N., Karpouzas, J., and Gregoriou, M. (1967). Diffculty in swallowing, with aspiration pneumonia in infancy. Arch. Dis. Childh., 42, 308.

Möbius, P. J. (1888). Ueber angeborene doppelseitige Abducensfacialis-Lahmung. Münch. med. Wschr., 35, 91 and 108.

Morgan, J. (1956). Neuromuscular inco-ordination of swallowing in the newborn. F. Laryng., 70, 294.

Mounier-Kuhn, P., and Persillon, A. (1955). Les troubles de la déglutition chez l'enfant. Pediatrie, 10, 37.

Nisenson, A., Isaacson, A., and Grant, S. (1955). Masklike facies with associated congenital anomalies (Möbius syndrome). f. Pediat., 46, 255.
Nitsch, K. (1954). Die-atonisch-hypertonische Dysphagie des Säuglings. Mschr. Kinderheilk., 102, 1.

Olmsted, R. W., Halfond, M. M., and Kirkpatrick, J. A. (1960). Isolated palatal paralysis. f. Pediat., 56, 795.

Oppenheim, H., and Vogt, C. (1911). Wesen und Lokalisation der kongenitalen und infantilen Pseudobulbärparalyse. $\mathcal{F}$. Psychol. Neurol. (Lpz.), 18, 293.

Palmer, J. M. (1962). Tongue thrusting: a clinical hypothesis. 7. Speech Dis., 27, 323.

Peiper, A. (1942). Die Schluckstörung. Mschr. Kinderheilk., 80, 37.

Peritz, G. (1902). Pseudobulbär-und Bulbär-paralysen des Kindersalters. Karger, Berlin.

Pettersson, G. (1961). Aglossia congenita with bony fusion of the jaws. Acta chir. scand., 122, 93.

Pruzansky, S., and Richmond, J. B. (1954). Growth of mandible in infants with micrognathia. Amer. F. Dis, Child., 88, 29.

Ptacek, L. J., Opitz, J. M., Smith, D. W., Gerritsen, T., and Waisman, H. A. (1963). The Cornelia de Lange syndrome. 7. Pediat., 63, 1000.

von Reuss, A. R. (1920). The Diseases of the Newborn. Bale and Danielsson, London.

Richmond, J. B., Eddy, E., and Green, M. (1958). Rumination: a psychosomatic syndrome of infancy. Pediatrics, 22, 49.

Riley, C. M. (1957). Familial dysautonomia. Advanc. Pediat., $9,157$.

Robin, P. (1923). La glossoptose: son diagnostic, ses conséquences, son traitement. F. Méd. Paris., 42, 235.

(1934). Glossoptosis due to atresia and hypotrophy of the mandible. Amer. F. Dis. Child., 48, 541.

Sawyer, J. E. H. (1911). Cases of inco-ordination of swallowing in infants. Bgham med. Rev., 70, 180.

Schaffer, A. J. (1960). Diseases of the Newborn. Saunders, Philadelphia.

Schwartz, A. B. (1953). Functional disorders of the larynx in early infancy. F. Pediat., 42, 457.

Silver, H. K. (1964). The de Lange syndrome. Amer. F. Dis. Child., 108, 523.

Stein, M. L., Rausen, A. R., and Blau, A. (1959). Psychotherapy of an infant with rumination. 7. Amer. med. Ass., 171, 2309.

Still, G. F. (1927). Common Disorders and Diseases of Childhood 5th ed. Oxford Medical Publications, London.

Takagi, Y., and Bosma, J. F. (1960). Disability of oral function in an infant associated with displacement of the tongue. Acta paediat. (Uppsala), 49, Suppl. 123, 62.

Tamm, A. (1925). Kau- und Schluckstörung mit familiărem Auftreten. Acta paediat. (Uppsala), 4, 195.

Thieffry, S., and Job, J. C. (1954). Troubles de la déglutition. pharyngée en pathologie infantile. Sem. Hôp. Paris, 30, 131.

Tratman, E. K. (1939). A case of bilateral ankylosis of the temporomandibular joint, alleged to be congenital. Brit. dent. F., 66, 225.

Upjohn, C. (1957). Multiple congenital nerve palsies. Proc. roy. Soc. Med., 50, 333.

Wilson, R. A., Kliman, M. R., and Hardyment, A. F. (1963). Ankyloglossia superior (palato-glossal adhesion in the newborn infant). Pediatrics, 31, 1051.

Worster-Drought, C. (1956). Congenital suprabulbar paresis. f. Laryng., 70, 453.

Zachary, R. B., and Emery, J. L. (1961). Failure of separation of larynx and trachea from the esophagus. Persistent esophagotrachea. Surgery, 49, 525.

Zellweger, H., and Schneider, H. J. (1968). Syndrome of hypotoniahypomentia-hypogonadism-obesity (HHHO) or Prader-Willi syndrome. Amer. F. Dis. Child., 115, 588.

Correspondence to Professor R. S. Illingworth, The Children's Hospital, Western Bank, Sheffield 10. 